\title{
Hepatocyte Growth Factor as a Key to Modulate Anti-Ulcer Action of Prostaglandins in Stomach
}

\author{
Morio Takahashi, ${ }^{\star}$ Shinichi Ota, ${ }^{\star}$ Yasuo Hata, ${ }^{\star}$ Yasuyo Mikami,, Noboru Azuma, ${ }^{\S}$ Toshikazu Nakamura," Akira Terano," \\ and Masao Omata* \\ *Second Department of Internal Medicine, Faculty of Medicine, University of Tokyo, Tokyo 113, Japan; ${ }^{\ddagger}$ Department of Laboratory \\ Medicine, Faculty of Medicine, University of Tokyo, Tokyo 113, Japan; ${ }^{\S}$ Department of Surgery, Misato Junshin Hospital, Misato, \\ Saitama 341, Japan; "Biomedical Research Center, Osaka University Medical School, Osaka 565, Japan; and ${ }^{\llbracket}$ Second Department of \\ Medicine, School of Medicine, Dokkyo University, Mibu, Tochigi 321-02, Japan
}

\begin{abstract}
Although the clinical efficacy of prostaglandins (PGs), especially on gastric mucosal injuries induced by nonsteroidal antiinflammatory drugs, is widely appreciated, their mechanism of action, apart from acid suppression, is quite unclear. In this study, we have established a primary culture system of human gastric fibroblasts and clearly demonstrated that PGs strongly induce the expression of hepatocyte growth factor (HGF) in the fibroblasts, which is mediated by PGE specific receptor, EP2 or EP4. Since HGF facilitates repair and protection of gastric epithelial cells in a paracrine manner, it is assumed that some of the beneficial effects of PGs may be mediated by HGF. To confirm this assumption, we established a simplified in vitro culture gastric mucosal model which consists of gastric epithelial cells and gastric fibroblasts. Using the model, we performed a round wound restitution assay. PGE1 remarkably accelerated restitution which was completely inhibited by antiHGF antibody, indicating that the action was mediated by HGF. To confirm these in vitro data, we further demonstrated that HGF mRNA expression is downregulated at the edges of nonsteroidal antiinflammatory drug-induced gastric ulcers where PGs should be depleted. In summary, we proposed that gastric fibroblasts are newly recognized targets of PGs, and HGF produced by human gastric fibroblasts may be a key factor for anti-ulcer action of PGs in the stomach. (J. Clin. Invest. 1996. 98:2604-2611.) Key words: nonsteroidal antiinflammatory drug • restitution • gastric ulcer • regeneration • gastric fibroblast
\end{abstract}

\section{Introduction}

A high incidence of gastric mucosal injuries, such as erosions, small submucosal hemorrhages, and gastric ulcers, is reported in patients administered nonsteroidal antiinflammatory drugs

Address correspondence to Morio Takahashi, M.D., 2nd Department of Internal Medicine, Faculty of Medicine, University of Tokyo, 7-3-1 Hongo, Bunkyo-ku, Tokyo 113, Japan. Phone: 81-3-3815-5411 x 3070; FAX: 81-3-3814-0021; E-mail: TAKAHASHI-2IM@H.U-TOKYO. AC.JP

Received for publication 19 June 1996 and accepted in revised form 25 September 1996.

J. Clin. Invest.

(C) The American Society for Clinical Investigation, Inc. 0021-9738/96/12/2604/08 \$2.00

Volume 98, Number 11, December 1996, 2604-2611
(NSAIDs). ${ }^{1}$ How NSAIDs induce gastric lesions has been attributed to various causes such as suppression of endogenous PGs, direct toxic action on gastric epithelial cells, and neutrophils (1). Among these factors, depletion of endogenous PGs has been postulated to play the major role (2). Therefore, it is assumed that PGs should be effective on NSAID-induced gastric mucosal impairment. Actually, many clinical studies have demonstrated the defensive effects of PGs on gastric mucosa (3) as well as effects of accelerating repair, especially on NSAID-induced injury $(4,5)$. However, side effects, including diarrhea and uterine contraction, make many physicians reluctant to prescribe them (6). To eliminate the side effects of PGs and preferably to obtain stronger effects, we need to know the mechanism of action of their clinical efficacy. The mechanism of efficacy is quite controversial. The only universally accepted mechanism is acid suppression, where the target is clearly demonstrated to be the parietal cells. However, acid suppression elucidates only a part of PG clinical efficacy. Therefore, it is important to identify the cellular targets of PGs and the mechanism, which includes not only their role in the mucosal defense but in facilitating the repair of gastric ulcers.

Levi et al. (7) reported that NSAIDs cause gastric mucosal injury by inhibiting mucosal cell proliferation. NSAID-induced gastric mucosal injury is reversed by PGs, indicating that the clinical efficacy of PGs is by promoting mucosal cell proliferation. However, their report concluded that how NSAIDs inhibit cell division and how PGs reverse that inhibition require further study (7). Our preliminary study suggested that PGs have no direct effect on the proliferation of gastric epithelial cells. Therefore, we postulated that the actions of PGs might be mediated by some growth factor.

We have demonstrated previously that hepatocyte growth factor (HGF) strongly stimulates the proliferation and migration of gastric epithelial cells in an in vitro primary culture system $(8,9)$. Studies from other laboratories have confirmed our findings (10). It has also been shown lately that HGF not only accelerates repair of gastric epithelial cells, but also protects against ethanol-induced gastric epithelial disruption (11). Immunohistochemical and reverse transcription (RT)-PCR studies have also demonstrated that HGF is specifically expressed by fibroblasts at the edges of human gastric ulcers, confirming the importance of HGF in gastric ulcer repair (9), which also suggests that HGF elicits the action through paracrine mecha-

1. Abbreviations used in this paper: BME, basal Eagle's medium; COX-2, cyclooxygenase 2; HGF, hepatocyte growth factor; NSAIDs, nonsteroidal antiinflammatory drugs; RT-PCR, reverse transcription PCR. 
nism. Therefore, regulation of HGF expression by gastric fibroblasts may be important in the repair and protection of gastric mucosa. Previously, HGF expression was shown to be upregulated by several inflammatory cytokines such as TNF $\alpha$ and IL- $1 \alpha$, using skin fibroblasts (12). Recently, Matsumoto et al. (13) demonstrated that PGs stimulated the expression of HGF in human skin fibroblasts. However, the regulation of HGF expression in gastric mucosal fibroblasts has never been addressed.

These facts prompt us to investigate the possibility that PGs might stimulate HGF expression in human gastric fibroblasts, and consequently the possible role played by HGF in the clinical efficacy of PGs. Therefore, in this study, in order to investigate the effect of PGs on HGF expression in gastric fibroblasts, we established a primary culture system of human gastric fibroblasts. To assess the effect of PGs on gastric mucosal restitution, we further established a simplified gastric mucosal model which consists of gastric epithelial cells and fibroblasts and we performed a round wound restitution assay. To confirm these in vitro studies, we also investigated HGF expression at the edges of NSAID-induced human gastric ulcer where PGs should be depleted, using competitive RT-PCR technique.

\section{Methods}

\section{In vitro study}

Reagents. PGE1, PGE2, and PGI2 analogue (stabilized PGI2, OP2507) were kindly donated by Ono Pharmaceutical Ltd. (Osaka, Japan). Human recombinant HGF was purified from the conditioned medium of Chinese hamster ovary cells transfected with an expression vector containing the complete human HGF cDNA (14). The reagents for gastric epithelial cell and fibroblast culture were as follows: Coon's modified Ham's F-12 medium (KC Biological Inc., Lenexa, KS), basal Eagle's medium (BME), MEM (Sigma, St. Louis, MO), Hepes buffer (Sigma), BSA (fraction V; Sigma), HBSS (Gibco Laboratories, Grand Island, NY), crude type I collagenase (Sigma), and EDTA (Sigma). A Megaprime DNA labeling kit was obtained from Amersham International (Buckinghamshire, United Kingdom), and Hybond- $\mathrm{N}^{+}$was also obtained from Amersham. A Quiaex DNA gel extraction kit was purchased from QIAGEN Inc. (Chatsworth, CA).

Determination of HGF protein. HGF was measured by ELISA with monoclonal and polyclonal antibody against human HGF (Institute of Immunology, Tokyo, Japan).

Cell culture. Human gastric mucosal fibroblasts were isolated from adult human stomach and cultured as follows. The gastric mucosa was obtained at surgery and stored in F-12 culture medium supplemented with $10 \% \mathrm{FBS}$ at $4^{\circ} \mathrm{C}$. Later, it was scraped bluntly, and minced into 2- to 3- $\mathrm{mm}^{2}$ pieces, which were incubated in BME containing crude type I collagenase $(0.35 \mathrm{mg} / \mathrm{ml})$. This was followed by incubation in BME containing $1 \mathrm{mM}$ EDTA and further incubation in the former solution, which was performed twice serially at $37^{\circ} \mathrm{C}$, $\mathrm{pH} 7.4$, in an atmosphere of $5 \% \mathrm{CO}_{2}$ and $95 \% \mathrm{O}_{2}$. Cells from the final incubation were washed in HBSS and cultured at $37^{\circ} \mathrm{C}$ in a moist atmosphere containing $5 \% \mathrm{CO}_{2}$. The culture medium was $\mathrm{F}-12$ medium supplemented with $10 \%$ heat inactivated $\left(56^{\circ} \mathrm{C}\right.$ for $\left.30 \mathrm{~min}\right) \mathrm{FBS}$ (Gibco Laboratories), $15 \mathrm{mM}$ Hepes buffer, $100 \mathrm{U} / \mathrm{ml}$ penicillin, 100 $\mathrm{U} / \mathrm{ml}$ streptomycin, and $5 \mu \mathrm{g} / \mathrm{ml}$ fungizone. The culture was maintained for at least $1 \mathrm{mo}$, after which the mucosal epithelial cells died and fibroblasts became predominant. During culture, F-12 medium with $10 \%$ FBS was changed twice a week. Subculture was performed up to four times whenever necessary using trypsin EDTA (Sigma).

Coculture of gastric fibroblasts and epithelial cells. Human gastric fibroblasts were prepared as described and were inoculated sparsely $\left(10^{4}\right.$ cells/well) onto 24 -well culture dishes. Rabbit gastric epithelial cells were prepared as described previously (15) and overinoculated onto the gastric fibroblasts. After $48 \mathrm{~h}$, confluent coculture was obtained.

$R T$-PCR for EP1, EP2, EP3, EP4, and IP. Total cellular RNA was isolated from cultured human gastric fibroblasts grown to confluence in 100-mm culture plates using RNAzol ${ }^{\mathrm{TM}} \mathrm{B}$ (Cinna/Biotecx, Friendswood, TX). $1 \mu \mathrm{g}$ of total RNA was reverse transcribed using M-MLV reverse transcriptase (GIBCO-BRL, Gaithersburg, MD), after which the product was denatured at $95^{\circ} \mathrm{C}$ for $5 \mathrm{~min}$ and cooled on ice. PCR was carried out in a final volume of $50 \mu \mathrm{l}$ reaction buffer containing $50 \mathrm{mM} \mathrm{KCl}, 10 \mathrm{mM}$ Tris (pH 8.3), $1.5 \mathrm{mM} \mathrm{MgCl}_{2}, 0.001 \%$ gelatin, $200 \mu \mathrm{M}$ each of dATP, dGTP, dCTP, and dTTP, and $2.5 \mathrm{U}$ of Taq polymerase (Promega, Madison, WI). Using $10 \mu$ l of the reverse transcription product, 30 cycles of amplification of the EP1, EP2, EP3, EP4, and IP first-strand cDNA were performed with $30 \mathrm{pmol}$ of each EP2 primer (sense: $5^{\prime 1198}$ ACACAGTCAGATGCCAGTAA ${ }^{1217} 3^{\prime}$; antisense: $5^{\prime}{ }^{1721}$ AAATAAAGGGTTCGCTAAGT ${ }^{1702} 3^{\prime}$ ) (16), EP4 primers (sense: $5^{\prime 527}$ AAGGAGCAG AAGGAGACGAC ${ }^{546} 3^{\prime}$; antisense: $5^{\prime 984}$ GTGGCGAGAATGAGGAAGGA ${ }^{965} 3^{\prime}$ ) (17), EP1 primers (sense: $5^{\prime 976}$ TCTACCTCCCTGCAGCGGCCACTG ${ }^{999} 3^{\prime}$; antisense: 5'1206 GAAGTGGCTGAGGCCGCTGTGCCGGGA ${ }^{1179} 3^{\prime}$ ), EP3 primers (sense: $5^{\prime 937} \mathrm{GAG}$ CACTGCAAGACACACACGGAG $\mathrm{G}^{960} 3^{\prime}$; antisense: $5^{\prime 1335}$ GATCTCCATGGGTATTAC TGACA$\mathrm{A}^{1312} 3^{\prime}$ ) (18), and IP primers (sense: $5^{\prime 524}$ GCCTTCTGCGTCCTCTTGTG ${ }^{543} 3^{\prime}$; antisense: $5^{\prime 908}{ }^{2}$ CATCTCACTGCTGCTGTCA ${ }^{889} 3^{\prime}$ ) (19). Each amplification cycle consisted of denaturation at $93^{\circ} \mathrm{C}$ for $30 \mathrm{~s}$, annealing for $45 \mathrm{~s}$, and polymerization at $72^{\circ} \mathrm{C}$ for $45 \mathrm{~s}$. The annealing temperatures are $59^{\circ} \mathrm{C}$ for $\mathrm{EP} 1,50.7^{\circ} \mathrm{C}$ for $\mathrm{EP} 2,64^{\circ} \mathrm{C}$ for $\mathrm{EP} 3$, $58.2^{\circ} \mathrm{C}$ for $\mathrm{EP} 4$, and $61.1^{\circ} \mathrm{C}$ for IP. PCR products $(10 \mu \mathrm{l})$ were electrophoretically separated on $2 \%$ agarose gel in $1 \times$ TAE buffer, after which the gel was stained with ethidium bromide $(0.5 \mu \mathrm{g} / \mathrm{ml})$.

Northern blot hybridization. Total cellular RNA was isolated from cultured human gastric fibroblasts using RNAzol ${ }^{\mathrm{TM}} \mathrm{B} .8 \mu \mathrm{g}$ of total RNA was electrophoresed on $1 \%$ agarose gel containing $0.66 \mathrm{M}$ formaldehyde and transferred to a Hybond $-\mathrm{N}^{+}$nylon membrane filter. As a probe for HGF mRNA, a 1.4-kb HGF cDNA fragment including the $3^{\prime}$-portion of the $\alpha$ subunit, the $\beta$ subunit, and part of the $3^{\prime}$-untranslated region was obtained from pRBC1 using the restriction enzyme EcoRI (20). The cDNA was labeled with $\left[\alpha-{ }^{32} \mathrm{P}\right] \mathrm{dCTP}$ by the random primer method using a Megaprime DNA labeling system, after which the membrane was hybridized with the cDNA probe at $65^{\circ} \mathrm{C}$ for $2 \mathrm{~h}$ in rapid hybridization buffer. Then the membrane was washed in $2 \times$ SSC with $0.1 \%$ SDS for $20 \mathrm{~min}$ at room temperature, followed by washing twice in $1 \times$ SSC with $0.1 \%$ SDS for $15 \mathrm{~min}$ at $65^{\circ} \mathrm{C}$. Finally, it was exposed to $\mathrm{x}$-ray film for $48 \mathrm{~h}$ at $-70^{\circ} \mathrm{C}$ using an intensifying screen.

Restitution model. The effect of PGE1 on restitution was studied using an in vitro gastric mucosal model which consists of gastric epithelial cells and fibroblasts. Confluent coculture of gastric epithelial cells and fibroblasts in 24-well culture plates was wounded with a custom-made scraper that produced a round wound with a diameter of $\sim 1.5 \mathrm{~mm}$ in each well. Then the monolayers were washed with fresh serum-free medium and were further cultured in fresh serum-free medium with PGE1 in the presence or absence of anti-human HGF antiserum.

A polyclonal antiserum was raised in rabbits against recombinant human HGF purified from the culture fluid of transformed Chinese hamster ovary cells. The antiserum reacted with h-rHGF and recognized both the $\alpha$ and $\beta$ chains, but did not react with rat or rabbit HGF (data not shown). Restitution of the coculture was assessed in a blind fashion to avoid observer bias. Accordingly, determination of the uncovered area was performed by a person who was unaware of the details of the experiment. Photomicrographs of the wounds were obtained at a 40-fold magnification using a Nikon microscope and camera. Then prints were made and wound area was cut out from each print and weighed. The weight was precisely related to the area, since the thickness of the prints was constant. Experiments were performed six times and the results were expressed as the mean \pm SE. 
Morphological observation was also performed at a stronger magnification.

\section{Human study}

$R T$-PCR for HGF and competitive RT-PCR. Total cellular RNA was isolated from biopsy tissue obtained from the edges of human gastric ulcer endoscopically, using RNAzol ${ }^{\mathrm{TM}} \mathrm{B}$ (Cinna/Biotecx). $1 \mu \mathrm{g}$ of total RNA was reverse transcribed using M-MLV reverse transcriptase (GIBCO-BRL), after which the product was denatured at $95^{\circ} \mathrm{C}$ for 5 min and cooled on ice. PCR was carried out in a final volume of $50 \mu \mathrm{l}$ reaction buffer containing $50 \mathrm{mM} \mathrm{KCl}, 10 \mathrm{mM}$ Tris $(\mathrm{pH} 8.3), 1.5 \mathrm{mM}$ $\mathrm{MgCl}_{2}, 0.001 \%$ gelatin, $200 \mu \mathrm{M}$ each of dATP, dGTP, dCTP, and dTTP, and $2.5 \mathrm{U}$ of Taq polymerase (Promega). Using $10 \mu \mathrm{l}$ of the reverse transcription product, 30 cycles of amplification of the HGF first-strand cDNA were performed with 20 pmol of each HGF primer (sense: $5^{\prime}$-979 $^{97 \text { CAGCGTTGGGATTCTCAGTAT }}{ }^{1000}{ }^{-3}$ ' from exon 8; antisense: $5^{\prime}$ - $^{1497}$ CCTATGTTTGTTCGTGTTGGA ${ }^{1518}-3^{\prime}$ from exon 13 , which should yield a single amplified band with a size of $539 \mathrm{bp}$. Each amplification cycle consisted of denaturation at $94^{\circ} \mathrm{C}$ for $30 \mathrm{~s}$, annealing at $52.2^{\circ} \mathrm{C}$ for $45 \mathrm{~s}$, and polymerization at $72^{\circ} \mathrm{C}$ for $45 \mathrm{~s}$. PCR products $(10 \mu \mathrm{l})$ were electrophoretically separated on $2 \%$ agarose gel in $1 \times$ TAE buffer, after which the gel was stained with ethidium bromide $(0.5 \mu \mathrm{g} / \mathrm{ml})$.

Competitive RT-PCR was performed to quantify the HGF mRNA expressed in normal gastric mucosa. Competitive RT-PCR is an established method of quantification of mRNA level, during which one set of primers is used to amplify both a target gene cDNA and another DNA fragment; in essence the second DNA fragment competes with the target DNA for the same primers and thus act as an internal standard. The competitor was constructed to be used as competitive internal standards in PCR amplification for quantitation of mRNA level of target genes, using the MIMICTM construction kit
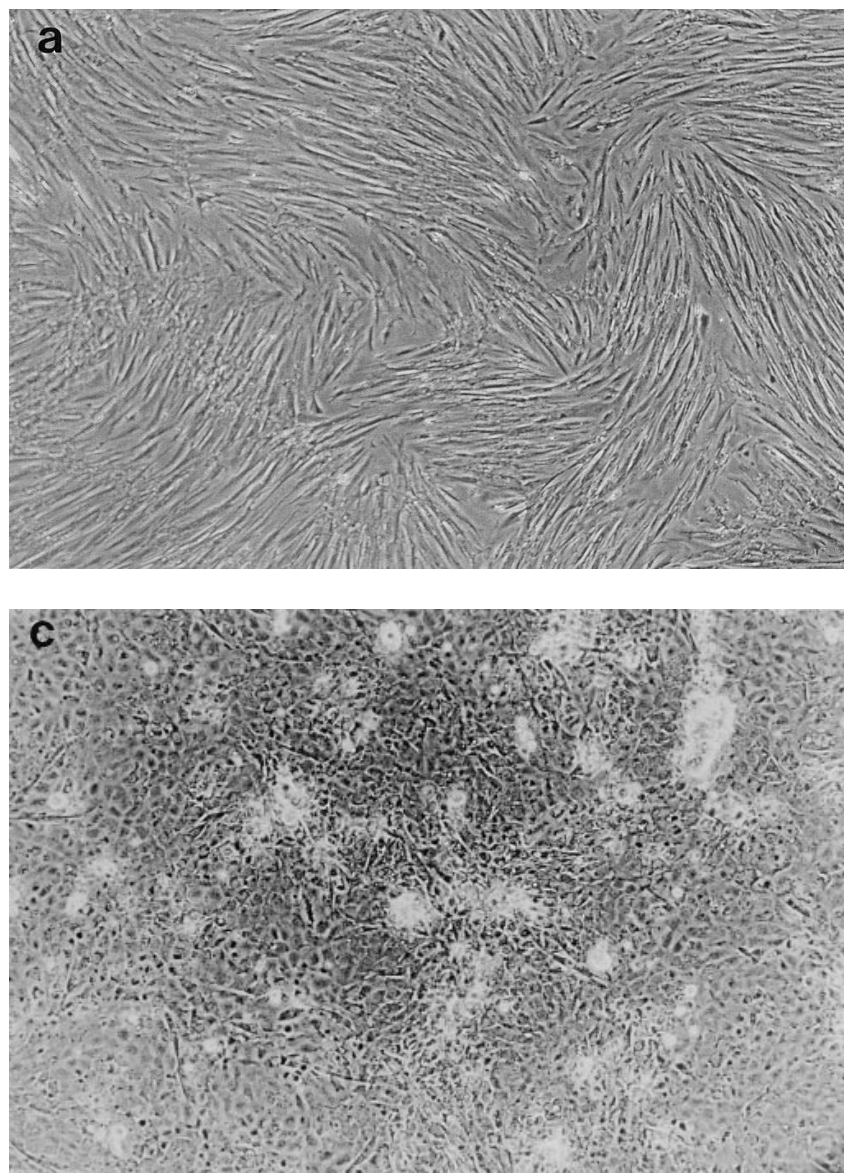

(Clontech Laboratories, Inc., Palo Alto, CA) according to the manufacturer's instruction. The competitor sequence is: 5'-CAGCGTTGGGATTCTCAGTAT TGTTATACAG GGAGATGAAA GGATGCACTT GCCTAGCCCT ACAGATTCCA AGTTTTATCG CACCCTGATG GAgGAGGAGG ACATGGAAGA CATTGTGGAT GCAGATGAGT ATCTTGTCCC ACACCAGGGC TTTTTCAACA TGCCCTCTAC ATCTCGGACT CCTCTTCTGA GTTCATTGAG CGCTACTAGC AACAATTCTG CTACAAACTG CATTGACAGA AATGGGCAGG GGCACCCTGT GAGGGAAGAG GCTTCCTGCC TGCTCCAGAG TATGTAAACC AGCTGATGCC CAAGAAACCA TCTACTGCCA TGGTCCAGAA TCAAAT TCCAACACGAACAAACATAGG- ${ }^{\prime}$. (Underlined are the target gene primer sequences.) Serial dilutions of the competitor are added to PCR amplification reactions containing constant amounts of the target cDNA samples. The competitor and target templates compete for the same primers in the reaction. By knowing the amount of the competitor added to the reaction, one can determine the mRNA level.

\section{Results}

Culture of human gastric mucosal fibroblasts and coculture of gastric fibroblasts and epithelial cells. Cultured cells formed subconfluent monolayers a month after inoculation. Then the culture was subcultured using trypsin EDTA. Detached cells were inoculated at the concentration of $10^{6}$ for a $10-\mathrm{cm}$ culture dish (Fig. $1 a$ ). Fig. $1 b$ demonstrates the phase-contrast microphotograph of sparsely populated gastric fibroblasts, onto which rabbit gastric epithelial cells were inoculated and coculture was obtained after $48 \mathrm{~h}$ (Fig. $1 c$ ).

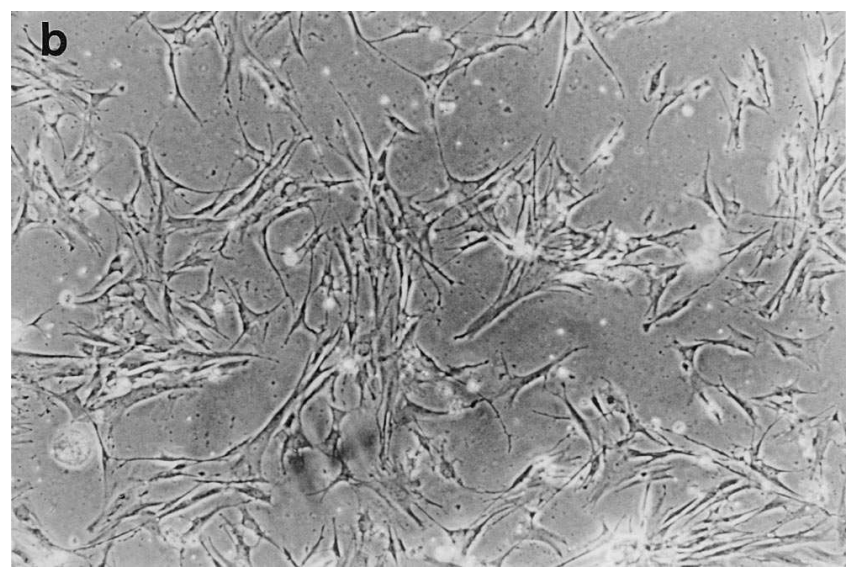

Figure 1. (a) Phase-contrast micrograph of human gastric fibroblasts in primary culture. $\times 40$. (b) Phase-contrast microphotograph of sparsely populated gastric fibroblasts. $\times 40$. (c) Coculture of gastric fibroblasts and epithelial cells. $\times 40$. Rabbit gastric epithelial cells were inoculated onto the sparsely populated gastric fibroblasts shown in $b$. Coculture of gastric fibroblasts and epithelial cells was obtained after $48 \mathrm{~h}$. 

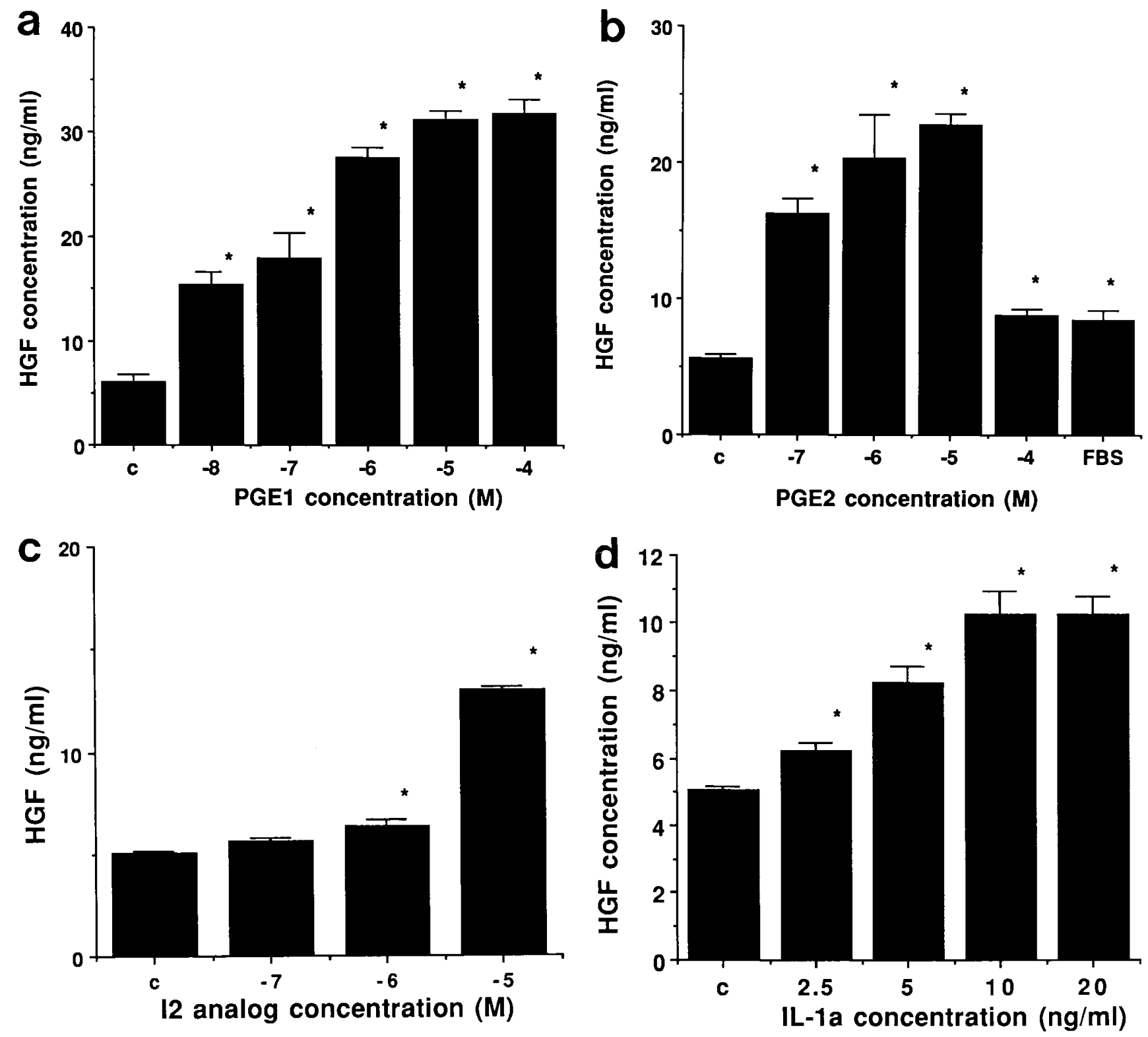

Figure 2. Effect of prostaglandins on production of HGF protein by human gastric fibroblasts, as compared with TNF $\alpha$ and IL-1 $\alpha$, as assessed by ELISA. (a) Dose dependency of HGF protein production induced by PGE1. PGE1 induced HGF production by gastric fibroblasts in a dosedependent manner. -4 denotes $10^{-4} \mathrm{M}$, etc. $(b)$ Dose dependency of HGF protein production induced by PGE2. PGE2 induced HGF production by gastric fibroblasts in a dose-dependent manner. -4 denotes $10^{-4} \mathrm{M}$, etc. (c) Dose dependency of HGF protein production induced by PGI2 analogue. PGI2 analogue induced HGF production by gastric fibroblasts in a dose-dependent manner. I2 analog denotes PGI2 analogue, and -5 denotes $10^{-5} \mathrm{M}$, etc. $(d)$ Dose dependency of HGF protein production induced by IL- $1 \alpha$. IL- $1 \alpha$ induced HGF production by gastric fibroblasts in a dose-dependent manner. IL-1a denotes IL-1 $\alpha$. (e) Dose dependency of HGF protein production induced by TNF $\alpha$. TNF $\alpha$ induced HGF production by gastric fibroblasts in a dose-dependent manner. TNFa denotes TNF $\alpha$. $(f)$ The time course of HGF production induced by various factors. $\left(g\right.$ ) Comparison among HGF protein production induced by $10^{-6} \mathrm{M}$ PGs and the maximum HGF production induced by TNF $\alpha$ $(10 \mathrm{ng} / \mathrm{ml})$ and IL-1 $\alpha(10 \mathrm{ng} / \mathrm{ml})$ which are obtained from the dose dependency graphs. We did not use the optimal concentration values of PGs which are obtained from the dose dependency graphs, since $10^{-5} \mathrm{M}$ or greater concentrations seemed too much for physiological sense. The potency was in the order of PGE1 $>$ PGE2 $\gg$ PGI2 analogue $>$ IL-1 $\alpha>$ TNF $\alpha$. I2anal denotes PGI2 analogue, IL-1 denotes IL-1 $\alpha$, and TNFa denotes TNF $\alpha$. Mean $+\mathrm{SE}, * P<0.01$ vs. control.

Effect of prostaglandins on production of HGF protein by gastric fibroblasts, as compared with TNF $\alpha$ and $I L-1 \alpha$. PGE1, PGE2, $\mathrm{I}_{2}$ analogue, TNF $\alpha$, and IL- $1 \alpha$ induced HGF protein production significantly in a dose-dependent fashion (Fig. 2, $a-$ $e$ ). Fig. $2 f$ shows the time course of HGF induction. Fig. $2 g$ demonstrates the comparison among HGF protein production induced by $10^{-6} \mathrm{M}$ PGs and the maximum HGF production induced by TNF $\alpha(10 \mathrm{ng} / \mathrm{ml})$ and IL-1 $\alpha(10 \mathrm{ng} / \mathrm{ml})$ which are obtained from the dose dependency graphs. We did not use the optimal concentration values of PGs which are obtained from the dose dependency graphs, since $10^{-5} \mathrm{M}$ or greater concentrations seemed too much for physiological sense. The potency 

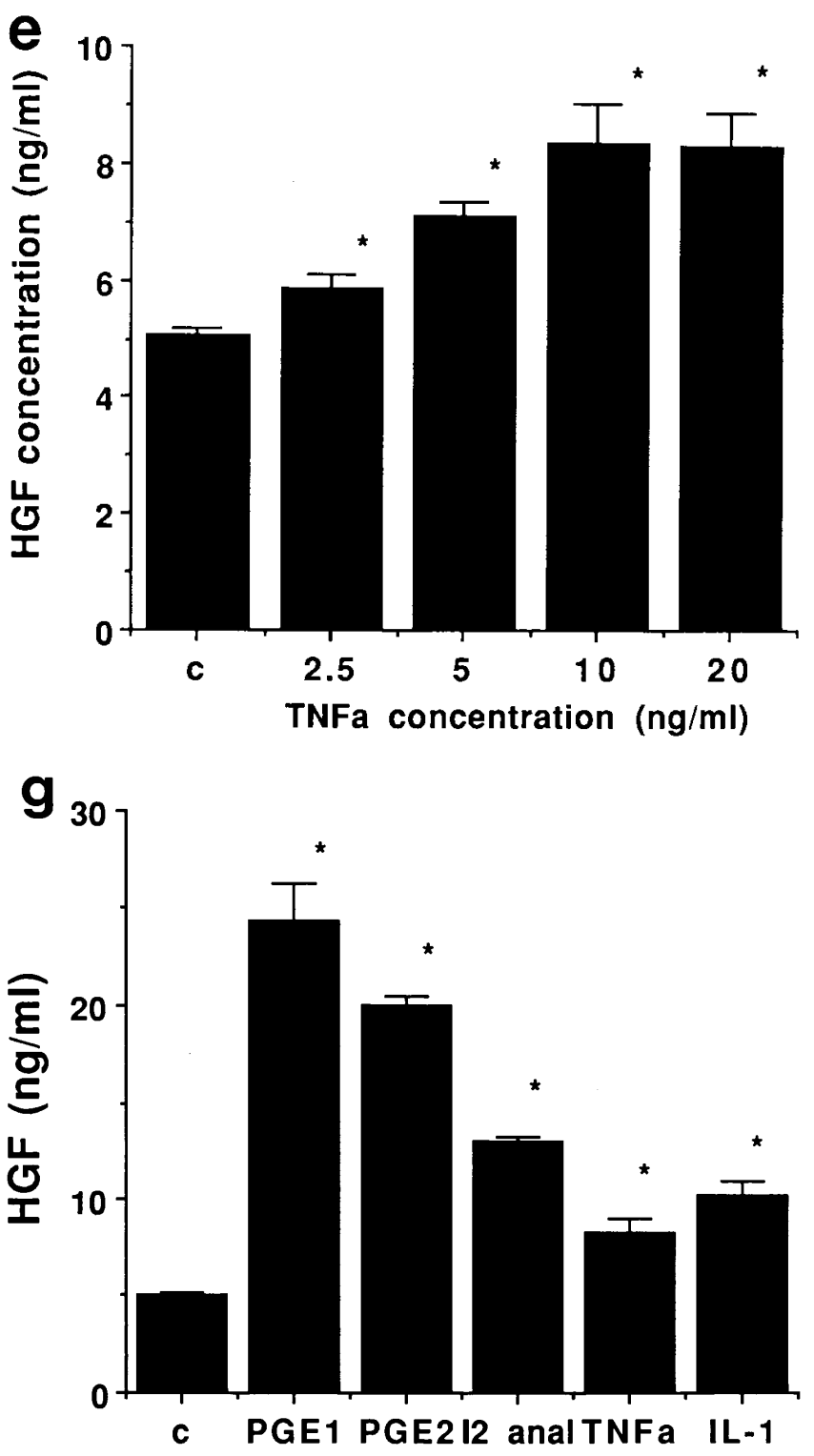

was in the order of PGE1 $>$ PGE2 $\gg$ PGI2 analogue $>$ IL-1 $\alpha>$ TNF $\alpha$. The HGF production induced by PGE1 and PGE2 was remarkably higher than that by TNF $\alpha$ and IL-1 $\alpha$, suggesting the significance of PGs in regulation of HGF in gastric mucosa.

Effect of PGE1 on expression of HGF $m R N A$ by gastric fibroblasts, as assessed by Northern blot hybridization. To confirm the effects of PGs on the HGF induction at the transcription level, we performed Northern blot hybridization. PGE1 induced HGF mRNA expression in a dose-dependent manner, suggesting that the mRNA induction is parallel to that of protein (Fig. 3).

Prostaglandin receptors, EP1, EP2, EP3, EP4, and IP $m R N A$ expression by gastric fibroblasts, as assessed by $R T$ $P C R$. To confirm that the effect of PGs on HGF induction is elicited by specific receptors, we investigated the expression of $\mathrm{EP} 1, \mathrm{EP} 2, \mathrm{EP} 3, \mathrm{EP} 4$, and IP in the gastric fibroblasts. RT-PCR showed the clear expression of EP2, EP3, and EP4 mRNA in the gastric fibroblasts, whereas no expression of EP1 or IP was seen (Fig. 4). The PCR products which correspond to EP2,

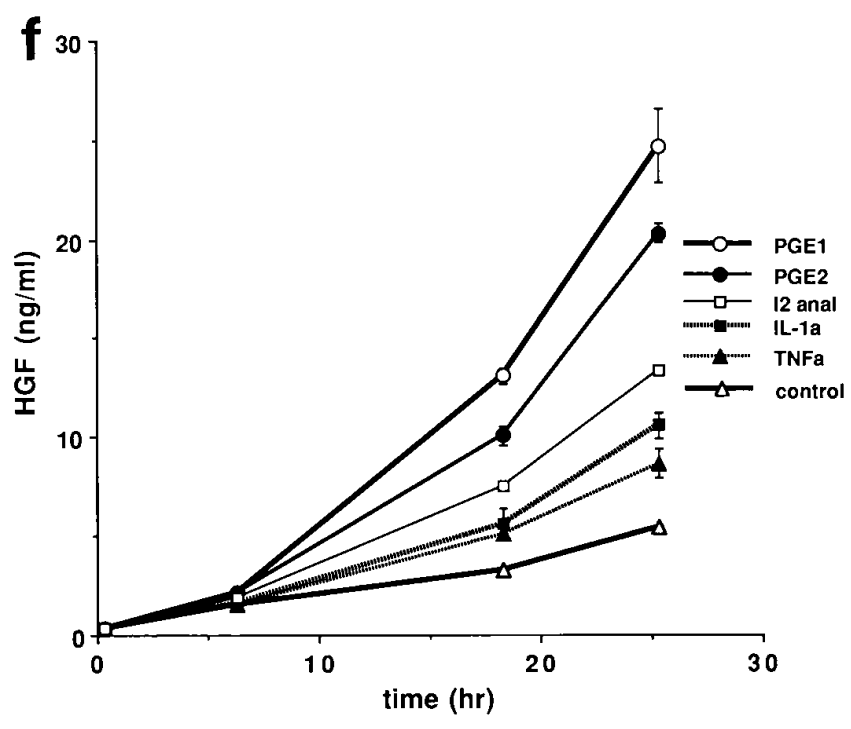

EP3, and EP4 were sequenced and confirmed to be the right bands.

Effect of exogenous cAMP on production of $H G F$ protein by gastric fibroblasts. PGE receptors are known to differ in their signal transduction mechanisms. EP3 inhibits adenylate cyclase. EP2 and EP4 stimulate adenylate cyclase and concomitantly increase cAMP. Therefore, induction of HGF by PGE should be mediated by cAMP. We investigated the effect of cAMP on the HGF production in gastric fibroblasts. Exogenous dbcAMP significantly facilitated production of HGF protein by gastric fibroblasts in a dose-dependent manner (Fig. 5), indicating that PGs induce HGF expression by adenylate cyclase activating pathway which is either an EP2- or an EP4mediated pathway.

Effect of PGE1 on restitution of simplified gastric mucosal model. Confluent coculture of gastric fibroblasts and gastric epithelial cells was wounded with a custom-made scraper that produced a round wound of $1.5 \mathrm{~mm}$ in diameter, followed by culture with PGE1 in the presence or absence of anti-HGF antibody. Epithelial cells from the edges of the wound gradually migrated to cover the defect. Fig. $6 a$ shows a series of phasecontrast microphotographs which demonstrates the time course

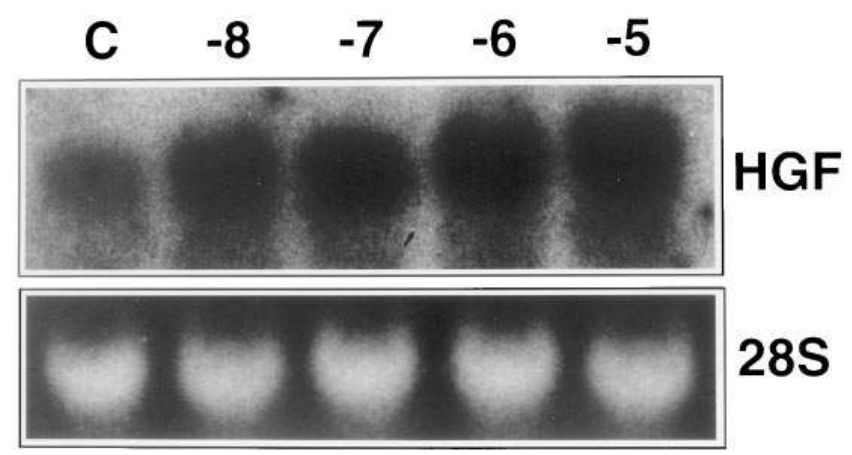

Figure 3. Effect of PGE1 on the expression of HGF mRNA by gastric fibroblasts, as assessed by Northern blot hybridization. The expression of HGF mRNA was significantly increased by PGE1 in a dose-dependent manner, indicating that the mRNA expression is parallel to the induction of $\mathrm{HGF}$ protein. 

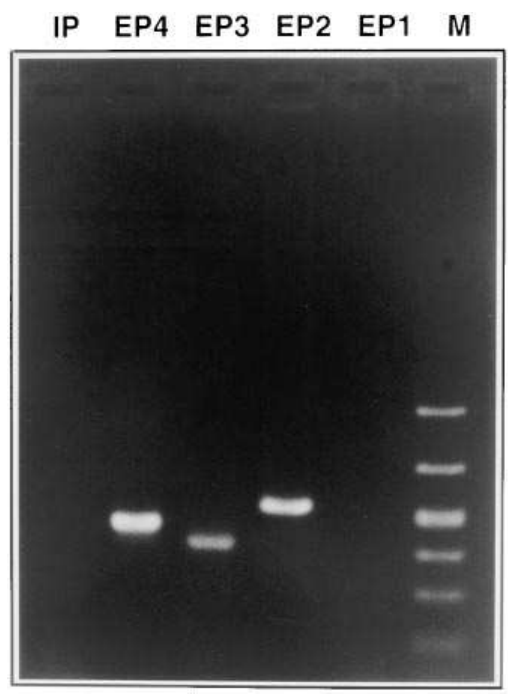

Figure 4. Expression of prostaglandin receptors, EP1, EP2, EP3, EP4, and IP mRNA by assessed by RT-PCR. The human gastric fibroblasts express EP2, EP3, and EP4 mRNA, whereas they do not express EP1 or IP. PCR products corresponding to EP2, EP3, and EP4 were sequenced and confirmed to be the correct bands. gastric fibroblasts, as

of wound restitution in the presence of PGE1, as compared with that in the absence of PGE1. The restitution was assessed by determining the denuded areas. Fig. $6 b$ shows the time course. PGE1 significantly facilitated restitution compared with control, which was completely inhibited by anti-HGF antibody, indicating that PGE1-induced restitution was mediated by HGF.

Expression of HGF $m R N A$ at the edges of NSAID-induced human gastric ulcers, as compared with ordinary gastric ulcers. We assessed the HGF mRNA expression by competitive RT-PCR technique, using biopsy samples obtained from gas-

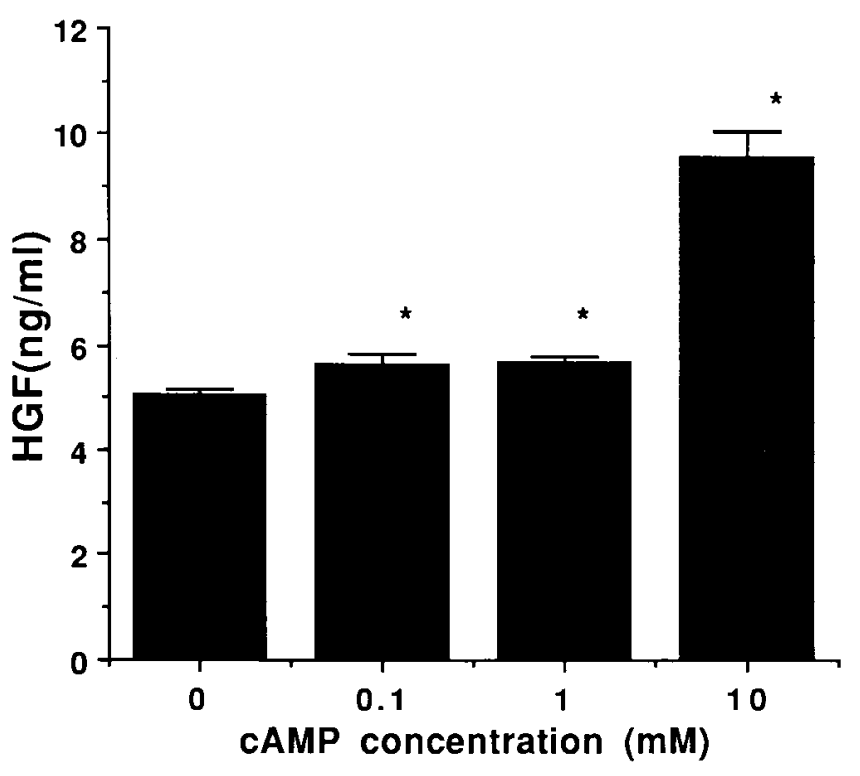

Figure 5. Effect of exogenous cAMP on production of HGF protein by gastric fibroblasts, as assessed by ELISA. DbcAMP facilitates production of HGF protein by gastric fibroblasts. Since it is known that EP2 and EP4 are the only PG receptors which stimulate adenylate cyclase and accordingly increase cAMP, these findings confirm that PGs induce HGF expression by either an EP2- or an EP4-mediated pathway. Mean $+\mathrm{SE}, * P<0.01$ vs. control.
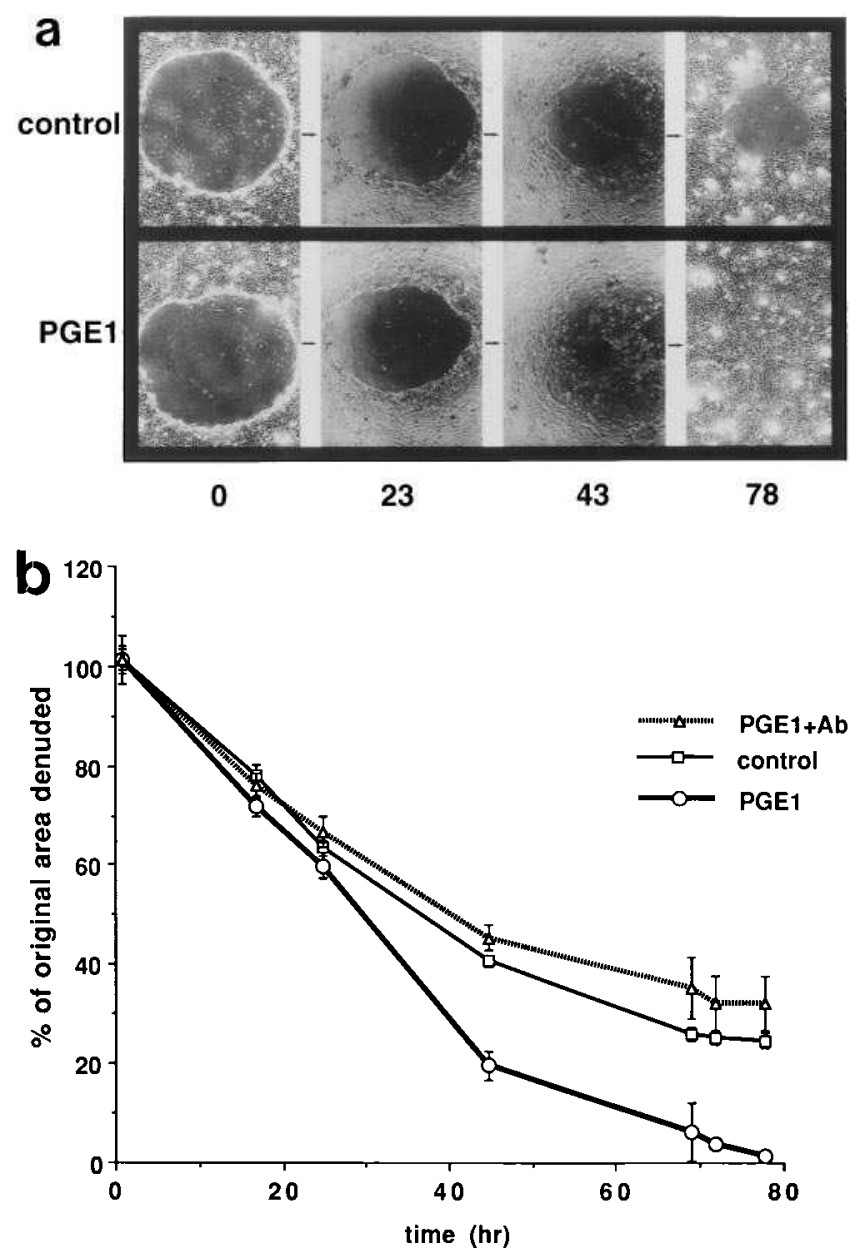

Figure 6. Effect of PGE1 on restitution of in vitro gastric mucosal model which consists of gastric epithelial cells and gastric fibroblasts. (a) Phase-contrast micrographs taken serially, showing the time course of wound restitution in the presence of PGE1 as compared with control (in hours). (b) Restitution was assessed by determining the residual uncovered area over time. The vertical axis indicates the residual uncovered area expressed as a percentage of the original wound area and the horizontal axis shows time. PGE1 facilitated restitution remarkably and significantly compared with the control, which is completely inhibited by anti-HGF antiserum. Each plot represents the mean \pm SE. PGE1 was $10^{-6} \mathrm{M}$. Ab denotes anti-HGF antiserum $(1: 1,000)$.

tric ulcer edges. None of five samples $(0 \%)$ from NSAIDs induced gastric ulcer edges (gastric ulcers of patients who were taking oxaprozin) expressed any HGF mRNA, at least to the extent that our system can detect. On the other hand, four out of five samples $(80 \%)$ from ordinary gastric ulcer edges expressed HGF mRNA, as much as $0.1-1.0 \mathrm{fmol} / 0.1 \mu \mathrm{g}$ total RNA (Fig. 7). The difference was statistically significant $(P<$ $0.001)$. We were able to follow up two of the five NSAIDinduced gastric ulcers, 2 and $3 \mathrm{wk}$ after termination of NSAID administration. Both edges revealed HGF mRNA expression $(0.1 \mathrm{fmol} / 0.1 \mu \mathrm{g}$ total RNA). (We were not able to follow up the rest of the NSAID-induced gastric ulcers.) These findings indicate that NSAIDs inhibited HGF expression at the edges of gastric ulcers, probably through depletion of PGs, which is in accordance with our in vitro data. 


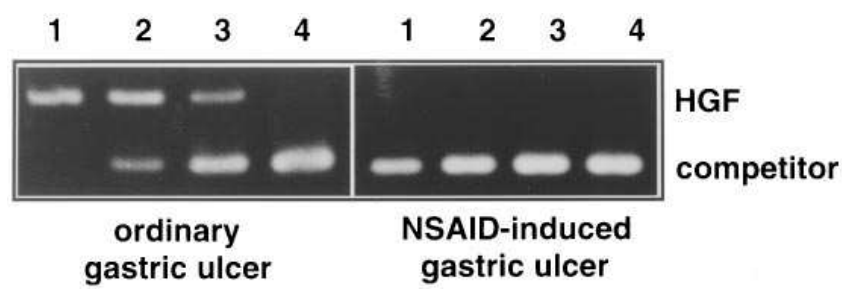

Figure 7. Representative demonstration of HGF mRNA expression in human tissue from the edge of an NSAID-induced gastric ulcer. Total RNA was extracted from biopsy samples obtained from gastric ulcer edges. Competitive PCR was performed to quantify the level of HGF expression, using the competitor which was constructed from neutral DNA fragment. HGF expression level of the edge of ordinal gastric ulcer is estimated at $6 \times 10^{7.5}$ copies $/ 0.1 \mu \mathrm{g}$ total RNA, while no expression was detected from that of NSAID-induced gastric ulcer. Lane $1,6 \times 10^{9}$ copies; lane $2,6 \times 10^{8}$; lane 3, $6 \times 10^{7}$; lane $4,6 \times$ $10^{6}$. HGF mRNA expression was supposed positive when the expression was estimated at $>6 \times 10^{6} \mathrm{copies} / 0.1 \mu \mathrm{g}$ total RNA. Four out of five biopsy samples from ordinal gastric ulcer edges revealed HGF mRNA expression, while none of five biopsies from NSAID-induced gastric ulcer edges revealed HGF mRNA expression. The difference between normal ulcer edges and NSAID-induced ulcer is statistically significant $(P<0.001)$.

\section{Discussion}

We have shown that PGs strongly induce HGF expression in gastric fibroblasts, which was demonstrated previously to provide HGF for gastric epithelial migration and proliferation (9). This regulation of HGF expression by the gastric fibroblasts is similar to that by skin fibroblasts (13). However, HGF induction by PGI2 analogue was not so remarkable in gastric fibroblasts as in skin fibroblasts, indicating a difference of regulation in fibroblasts of different origins. We have also investigated if each strain of gastric fibroblasts from different individuals is the same. The initial HGF production levels without stimulation were different from each other but the regulating patterns had the same tendency (data not shown).

PGs usually elicit their various effects via specific receptormediated pathways. Therefore, it is assumed that these actions of PGs in the stomach are also elicited by specific receptors. Pharmacological studies show that there are four specific receptors of PGE: EP1, EP2, EP3, and EP4 (21), which are thought to differ in their signal transduction mechanisms. EP1 seems to be coupled to $\mathrm{Ca}^{2+}$ mobilization, EP2 and EP4 stimulate adenylate cyclase, and EP3 inhibits adenylate cyclase. EP2 and EP4 are coupled to the same signal transduction pathway, stimulating adenylate cyclase, and concomitantly increasing cellular cAMP. In this study, we demonstrated the expression of EP2, EP3, and EP4 in the gastric fibroblasts which are all related to cAMP. At the same time, exogenous cAMP significantly induced HGF production in the fibroblasts, indicating that HGF expression may be induced by cAMP stimulation. These findings suggest that the action was mediated by either EP2 or EP4. To obtain profitable PG derivatives in the sense of association between PG and HGF, we should consider which receptor they bind. However, present PG derivatives seem to have been developed without the consideration. Unpublished data suggest that a clinically used PG derivative binds to EP3 instead of EP2 or EP4, which might add an adverse character to the medicine. In this sense, the present study will assist pharmaceutical efforts in the development of safer and more potent mucosal protectants.

We have demonstrated that the effect of PGE1 and PGE2 on HGF expression is remarkably stronger than IL-1 $\alpha$ or $\mathrm{TNF} \alpha$ which had been regarded previously as the most potent upregulator of HGF (12), indicating the possibility that PG may be the main regulator in the stomach. The gastric fibroblasts as well as gastric epithelial cells also remarkably produce PGE2 (unpublished data). Therefore, PGs may be the endogenous defensive factors regulating HGF expression. Actually, our human study shows that HGF mRNA expression at the gastric ulcer edges was downregulated when NSAIDs deplete the endogenous PGs. Of course, we cannot discount the possibility that NSAIDs may have a direct effect on HGF transcription or that they may elicit the downregulation through other pathways, but taken together with our in vitro data, the HGF downregulation at gastric ulcer edges may well be explained by PG depletion. In any event, the result is in accordance with our in vitro studies, although further studies are indispensable for interpretation of our result in the human study. The present study sheds light on understanding of the association among NSAIDs, PGs, HGF, and gastric mucosal protection.

The association between PGs and HGF might be a new view to explain the clinical efficacy of PGs in stomach. Besides, it further indicates the possibility that HGF might modulate various PG-induced phenomena. PGE2 was reported to be involved in liver regeneration (22). Since EP2 was detected in liver (23), the PG-induced liver regeneration may be also through stimulation of adenylate cyclase. As HGF is an established factor for liver regeneration, these reports, together with our findings, indicate further that PG-induced liver regeneration might be mediated by HGF.

Various clinical reports suggest that NSAIDs, which are known to inhibit cyclooxygenase 2 (COX-2), a key enzyme to produce inducible prostaglandins, reduce the sizes of colon adenomas (24) and risks of colon cancers $(25,26)$, where overexpression of COX-2 mRNA and protein is reported $(27,28)$. Lately, Tsujii et al. (29) reported that overexpression of COX2 may lead to inhibition of butyrate-induced apoptosis of the cells, which is reversed by NSAIDs. The exact mechanisms for the actions of COX-2 and NSAIDs are not understood presently. Our findings might shed significant light on the matter in the sense that the growth factor that is directly involved in cell proliferation is regulated by PGs which are induced by COX-2 and reduced by NSAIDs.

In conclusion, this report demonstrated that PGs strongly induce HGF expression in gastric fibroblasts and that HGF may modulate the clinical efficacy of PGs in stomach.

\section{Acknowledgments}

We wish to thank Naoko Sasaki for her excellent technical assistance.

This work was supported in part by a grant from Shirakawa Research Fund.

\section{References}

1. Hollander, D. 1994. Gastrointestinal complications of nonsteroidal antiinflammatory drugs: prophylactic and therapeutic strategies. Am. J. Med. 96: 274-281.

2. McCarthy, D.M. 1995. Mechanism of mucosal injury and healing: the role of non-steroidal anti-inflammatory drugs. Scand. J. Gastroenterol. 30(Suppl. 208):24-29. 
3. Robert, A. 1979. Cytoprotection by prostaglandins. Gastroenterology. 77 : 761-767.

4. Roth, S., N. Agrawal, M. Mahowald, H. Montoya, D. Robbins, S. Miller, E. Nutting, E. Woods, M. Crager, C. Nissen, and E. Swabb. 1989. Misoprostol heals gastroduodenal injury in patients with rheumatoid arthritis. Arch. Intern. Med. 149:775-779.

5. Silverstein, F.E., D.Y. Graham, J.R. Senior, H.W. Davies, B.J. Struthers, R.M. Bittman, and G.S. Geis. 1995. Misoprostol reduces serious gastrointestinal complications in patients with rheumatoid arthritis receiving nonsteroidal anti-inflammatory drugs: a randomized, double-blind, placebo-controlled trial. Ann. Intern. Med. 123:241-249.

6. Walt, R.P. 1992. Misoprostol for the treatment of peptic ulcer and antiinflammatory-drug-induced gastroduodenal ulceration. N. Engl. J. Med. 327: 1575-1580.

7. Levi, S., R.A. Goodlad, C.Y. Lee, G. Stamp, M.J. Walport, N.A. Wright, and H.J.F. Hodgson. 1990. Inhibitory effect of non-steroidal anti-inflammatory drugs on mucosal cell proliferation associated with gastric ulcer healing. Lancet. 336:840-843.

8. Takahashi, M., S. Ota, A. Terano, K. Yoshiura, M. Matsumura, Y. Niwa, T. Kawabe, T. Nakamura, and M. Omata. 1993. Hepatocyte growth factor induces mitogenic reaction to the rabbit gastric epithelial cells in primary culture. Biochem. Biophys. Res. Commun. 191:528-534.

9. Takahashi, M., S. Ota, T. Shimada, E. Hamada, T. Kawabe, T. Okudaira, M. Matsumura, N. Kaneko, A. Terano, T. Nakamura, and M. Omata. 1995. Hepatocyte growth factor is the most potent endogenous stimulant of rabbit gastric epithelial cell proliferation and migration in primary culture. J. Clin. Invest. 95:1994-2003.

10. Watanabe, S., M. Hirose, X.-E. Wang, K. Maehiro, T. Murai, O. Kobayashi, A. Nagahara, and N. Sato. 1994. Hepatocyte growth factor accelerates the wound repair of cultured gastric mucosal cells. Biochem. Biophys. Res. Commun. 199:1453-1460.

11. Takahashi, M., S. Ota, Y. Hata, K. Ogura, M. Kurita, A. Terano, T. Nakamura, and M. Omata. 1996. Constitutive expression of hepatocyte growth factor may maintain the sheet construction of gastric epithelial cells through facilitating actin-myosin contractile system. Biochem. Biophys. Res. Commun. 214:40-46.

12. Matsumoto, K., H. Okazaki, and T. Nakamura. 1992. Up-regulation of hepatocyte growth factor gene expression by interleukin-1 in human skin fibroblasts. Biochem. Biophys. Res. Commun. 188:235-245.

13. Matsumoto, K., H. Okazaki, and T. Nakamura. 1995. Novel function of prostaglandins as inducer of gene expression of HGF and putative mediators of tissue regeneration. J. Biochem. 117:458-464.

14. Nakamura, T., T. Nishizawa, M. Hagiya, T. Seki, M. Shimonishi, A. Sugimura, K. Tashiro, and S. Shimizu. 1989. Molecular cloning and expression of human hepatocyte growth factor. Nature (Lond.). 342:440-443.

15. Ota, S., A. Terano, and H. Hiraishi. 1990. A monolayer culture of gastric mucous cells from adult rabbits. Gastroenterol. Jpn. 25:1-7.
16. Regan, J.W., T.J. Bailey, D.J. Pepperl, K.L. Pierce, A.M. Bogardus, J.E. Donello, C.E. Fairbairn, K.M. Kedzie, D.F. Woodward, and D.W. Gil. 1994 Cloning of a novel human prostaglandin receptor with characteristics of the pharmacologically defined EP2 subtype. Mol. Pharmacol. 46:213-220.

17. Bastien, L., N. Sawyer, R. Grygorczk, K.M. Metters, and M.A. Adam. 1994. Cloning, functional expression and characterization of the human prostaglandin E2 receptor EP2 subtype. J. Biol. Chem. 269:11873-11877.

18. Pazit, B., L.J. Crofford, R.L. Wilder and T. Hla. 1995. Induction of vascular endothelial growth factor expression in synovial fibroblasts by prostaglandin E and interleukin-1: a potential mechanism for inflammatory angiogenesis. FEBS Lett. 372:83-87.

19. Katsuyama, M., Y. Sugimoto, T. Namba, A. Irie, M. Negishi, S. Narumiya, and A. Ichikawa. 1994. Cloning and expression of a cDNA for the human prostacyclin receptor. FEBS Lett. 344:74-78.

20. Tashiro, K., M. Hagiya, T. Nishizawa, T. Seki, M. Shimonishi, S. Shimizu, and T. Nakamura. 1990. Deduced primary structure of rat hepatocyte growth factor and expression of the mRNA in rat tissues. Proc. Natl. Acad. Sci. USA. 87:3200-3204.

21. Coleman, R.A., S.P. Grix, S.A. Head, J.B. Louttit, A. Mallett, and R.L.G. Sheldrick. 1994. A novel inhibitory receptor in piglet saphenous vein Prostaglandins. 47:151-168.

22. Tsujii, H., Y. Okamoto, E. Kikuchi, M. Matsumoto, and H. Nakano. 1993. Prostaglandin E2 and rat liver regeneration. Gastroenterology. 103:495499.

23. Katsuyama, M., N. Nishigaki, Y. Sugimoto, K. Morimoto, M. Negishi, S. Narumiya, and A. Ichikawa. 1995. The mouse prostaglandin E receptor EP2 subtype: cloning, expression, and Northern blot analysis. FEBS Lett. 372:151156.

24. Giardiello, F.M., S.R. Hamilton, A.J. Krush, S. Piantadosi, L.M. Hykind, P. Celano, S.V. Booker, C.R. Robinson, and J.A. Offerhaus. 1993. Treatment of colonic and rectal adenomas with sulindac in familial adenomatous polyposis. N. Engl. J. Med. 328:1313-1316.

25. Giovannucci, E., E.B. Rimm, M.J. Stampher, G.A. Colditz, A. Ascherio, and W.C. Willet. 1994. Aspirin use and the risk for colorectal cancer and adenoma in male health professionals. Ann. Intern. Med. 121:241-246.

26. Muscat, J.E., S.E. Stellman, and E.L. Wynder. 1994. Nonsteroidal antiinflammatory drugs and colorectal cancer. Cancer (Phila.). 74:1847-1854.

27. Eberhart, C.E., R.J. Coffey, A. Radhika, F.M. Giardiello, S. Ferrenbach, and R.N. DuBois. 1994. Up-regulation of cyclooxygenase 2 gene expression in human colorectal adenomas and adenocarcinomas. Gastroenterology. 107:1183-1188.

28. Kargman, S., G. O’Neill, P. Vickers, J. Evans, J. Mancini, and S. Jothy. 1995. Expression of prostaglandin G/H synthase-1 and -2 protein in human colon cancer. Cancer Res. 55:2556-2559.

29. Tsujii, M., and R.N. DuBois. 1995. Alterations in cellular adhesion and apoptosis in epithelial cells overexpressing prostaglandin endoperoxide synthase 2. Cell. 83:493-501. 